\title{
Intradural lumbar disc herniation after full- endoscopic lumbar discectomy using the interlaminar approach: case report
}

\author{
Takeshi Hori, Kazuo Ohmori, Koichiro Ono \\ Center for Spinal Surgery, Nippon Koukan Hospital, 1-2-1 Koukandori, Kawasaki-ku, Kawasaki 210-0852, Japan.
}

Correspondence to: Dr. Takeshi Hori, Center for Spinal Surgery, Nippon Koukan Hospital, 1-2-1 Koukandori, Kawasaki-ku, Kawasaki 210-0852, Japan. E-mail: takhori1030@gmail.com

\begin{abstract}
How to cite this article: Hori T, Ohmori K, Ono K. Intradural lumbar disc herniation after full-endoscopic lumbar discectomy using the interlaminar approach: case report. Mini-invasive Surg 2019;3:21. http://dx.doi.org/10.20517/2574-1225.2019.15
\end{abstract}

Received: 9 May 2019 First Decision: 9 Jul 2019 Revised: 10 Jul 2019 Accepted: 15 Jul 2019 Published: 20 Jul 2019

Science Editor: Giulio Belli Copy Editor: Jia-Jia Meng Production Editor: Jing Yu

\begin{abstract}
A 67-year-old man complained of the sudden onset of disabling pain in his right leg. He had already undergone full-endoscopic lumbar discectomy, interlaminar (FELD-IL) approach twice for lumbar disc herniation (LDH) at the L4/5 level. MRI showed recurrence of LDH at L4/5 level. Intradural masses were also suspected at the L4 vertebral level. Discography at the L4/5 disc showed contrast medium leakage from the disc to the subarachnoid space. Operation was performed and fragments of the herniated disc were carefully removed under a surgical microscope. The ventral dura mater could be seen adhering to the $L 4 / 5$ disc. This report is the first documentation of intradural LDH after FELD-IL. Although FELD is less invasive than previous procedures, adhesion between dura mater and surrounding tissues may occur. It is most important to apply discography to confirm the presence of a hole between the intradural space and the disc.
\end{abstract}

Keywords: Intradural lumbar disc herniation, full-endoscopic lumbar discectomy, discography

\section{INTRODUCTION}

Intradural lumbar disc herniation (LDH) is rare, with a reported incidence of $0.26 \%-0.30 \%$ of all cases of $\mathrm{LDH}^{[1,2]}$. The first report of intradural LDH was presented by Dandy in $1942^{[3]}$. Several etiopathologies of intradural LDH have been suggested, including adhesion between the ventral dura and posterior

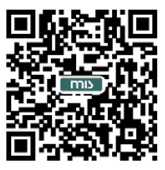




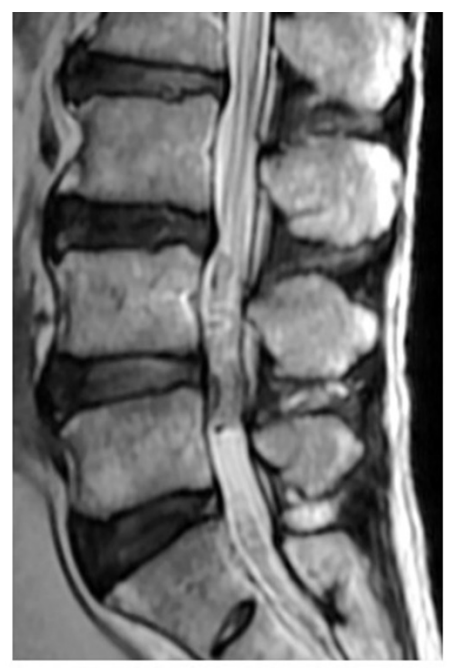

Figure 1. Preoperative magnetic resonance imaging, T2-weighted sagittal image

longitudinal ligament associated with congenital or chronic inflammation after previous surgery ${ }^{[1,4]}$, congenital reduction in dural thickness, and congenital stenosis of the vertebral canal ${ }^{[5]}$.

Full-endoscopic lumbar discectomy (FELD) is a minimally invasive technique for treating LDH. FELD has recently become widely used after being reported by Ruetten $e t$ al.$^{[6]}$ in 2008 . Three approaches are used with FELD to treat LDH: transforaminal, posterolateral, and interlaminar (IL). To date, there are no reports of intradural LDH in patients following FELD-IL. Herein, we describe a case of intradural LDH after FELD-IL and discuss the specific features of diagnostic imaging, its etiopathology, and the surgical findings.

\section{CASE REPORT}

A 67-year-old man complained of the sudden onset of disabling pain in his right leg. He was admitted to our hospital. He had undergone FELD-IL twice before for LDH at the L4/5 level, 2 years and 1 year ago, respectively. There was no injury to the dura matter during the previous operations. The straight leg raising test was positive at $60^{\circ}$ on the right side. Neurological examination demonstrated no paralysis and no sensory disturbance in his leg. There was no dysuria. Magnetic resonance imaging (MRI) showed LDH at the L4/5 level and a redundant cauda equina [Figure 1]. Intradural masses were also suspected at the L4 level. Computed tomography (CT) after myelography clearly showed an intradural mass from L4 to the sacral level [Figure 2]. It was suspected to be intradural disc herniation or a spinal tumor. Discography and CT discography showed leakage of contrast medium from the disc space to the subarachnoid space [Figures 3 and 4]. Based on these findings, we strongly suspected intradural LDH.

Laminectomy from L4 to S1 was performed, exposing a bulging dural sac at the L4/5 level. Durotomy was performed at the midline, and the herniated disc was fragmented [Figure 5]. These fragments were carefully removed under a surgical microscope until the adhesion between the herniated disc and the cauda equina was disrupted and the defect in the dura mater apparent [Figure 6]. The ventral dura was strongly adherent to the $\mathrm{L} 4 / 5$ disc.

The patient reported alleviation of his leg pain immediately after the surgery. Postoperative MRI showed complete removal of the intradural LDH. 


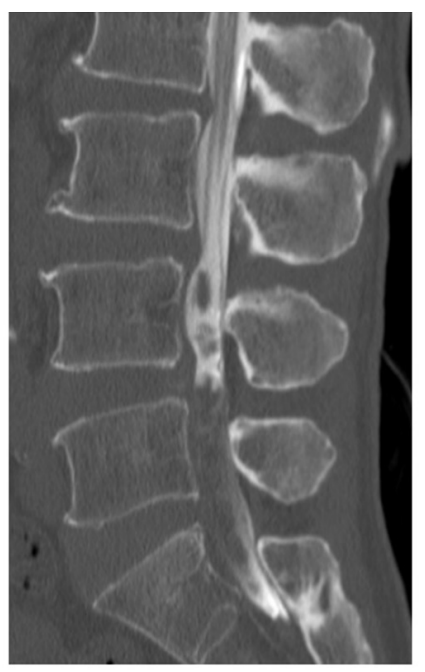

Figure 2. Computed tomography after myelography, sagittal image. An intradural mass was observed from L4 to the sacral level

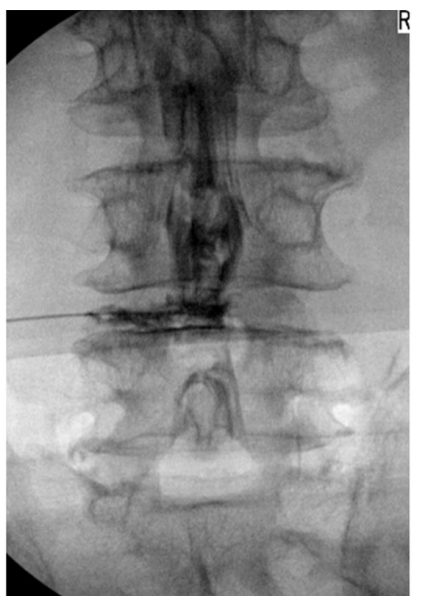

Figure 3. Discography at the L4/5 level. Contrast medium was not contained within the disc as it spread intrathecally with a myelographic appearance
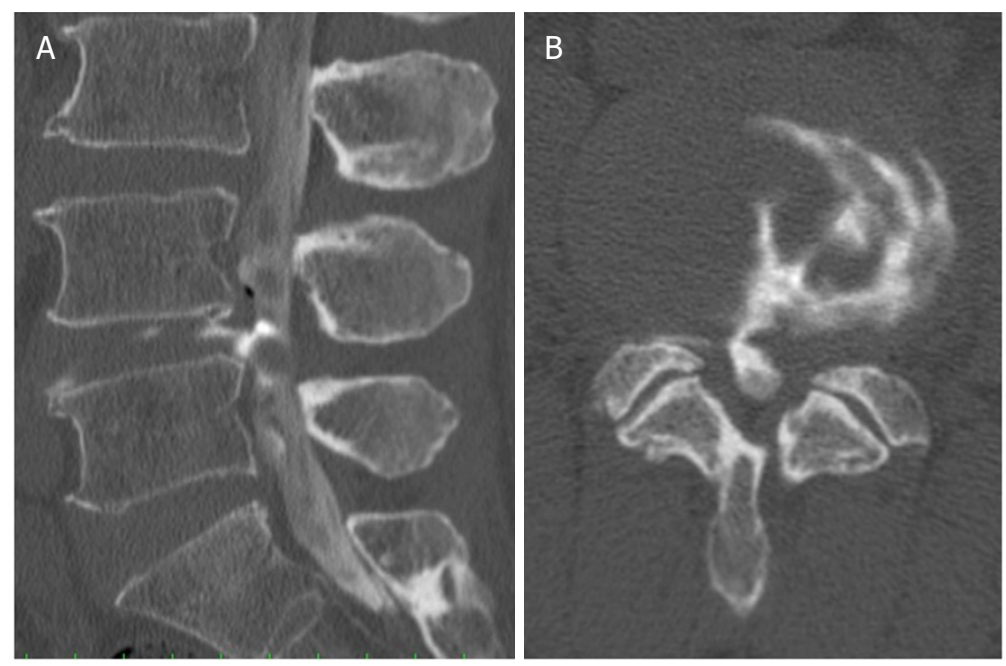

Figure 4. Computed tomography after discography. A: sagittal image; B: axial image 


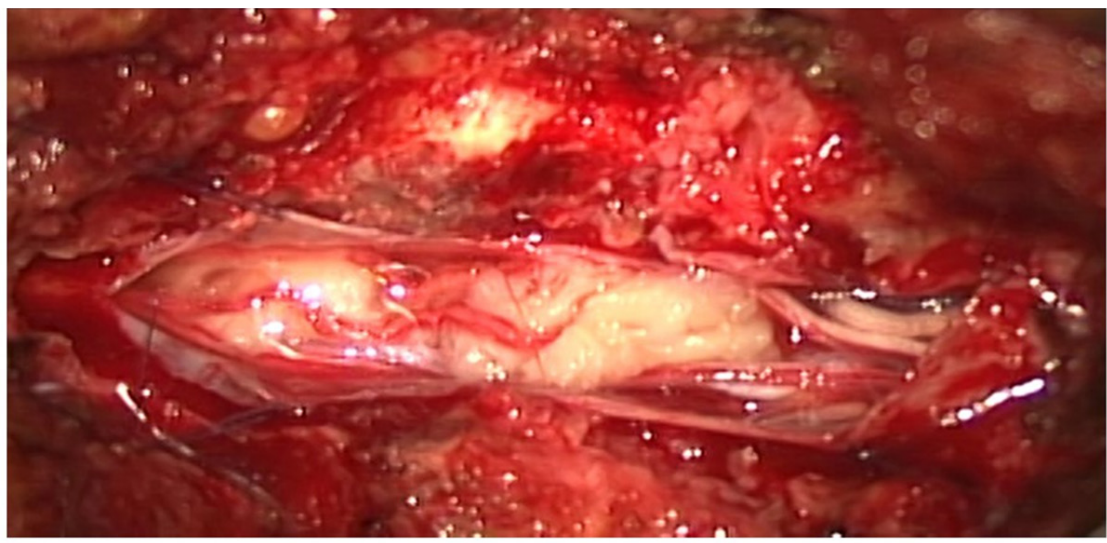

Figure 5. Intraoperative microscopic image reveals an intradural herniated mass

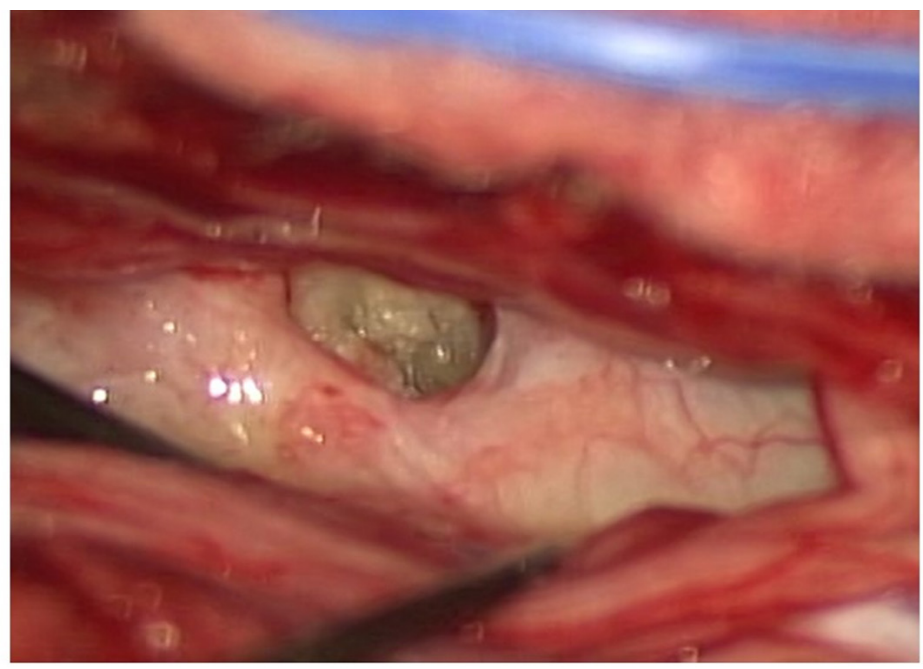

Figure 6. Intraoperative microscopic image reveals a defect in the ventral dura

\section{DISCUSSION}

First reported in 2008 by Ruetten et al. ${ }^{[6]}$, FELD is a minimally invasive technique for treating LDH. Tamaki et al..$^{[7]}$ later reported the occurrence of intradural LDH after FELD, but the transforaminal approach was used, and a ventral dural tear was observed during the operation. Our present report is the first documentation of intradural LDH after FELD-IL.

Although FELD is less invasive than previous procedures (e.g., micro-endoscopic or open surgery), adhesion between the dura mater and surrounding tissues may occur after FELD, as in the present case. The re-operation should be performed carefully even if the previous operation procedure was FELD. Matsumoto et al.$^{[8]}$ reported that the pathophysiology of intradural LDH is typically attributed to adhesion between the annulus fibrosus, the posterior longitudinal ligament, and the dura mater after local inflammation or a prior operation. It is quite possible that intradural LDH could occur after FELD-IL even though FELD is less invasive and there was no dural tear.

Several radiological features of intradural LDH - rim enhancement of the herniated disc on gadoliniumenhanced MRI, beak-like appearance on T2-weighted images - have been reported previously. However, these radiological features are not conclusive for diagnosing intradural LDH. The most important 
diagnostic step is to demonstrate a hole between the intradural space and the disc space. A few reports have described discography for preoperative intradural $\mathrm{LDH}^{[9,10]}$. Benyamin et al. ${ }^{[9]}$ reported a case of intradural LDH incidentally diagnosed during routine discography. In the present case, we performed discography to distinguish intradural LDH from other spinal pathologies, such as neurinoma and arachnoid cyst, among others.

In conclusion, preoperative diagnosis of intradural $\mathrm{LDH}$ is important for surgical planning. Physical examination for intradural LDH is similar to that for common LDH. Image findings, especially via discography, are important for establishing a definitive diagnosis of intradural LDH.

\section{DECLARATIONS}

\section{Authors' contributions}

Conception and design: Hori T, Ohmori K

Clinical treatment: Hori T, Ohmori K, Ono K

Manuscript writing: Hori T

Final approval of manuscript: Hori T, Ohmori K

\section{Availability of data and materials}

Not applicable.

\section{Financial support and sponsorship}

None.

\section{Conflicts of interest}

All authors declared that there are no conflicts of interest.

\section{Ethical approval and consent to participate}

All procedures used in the present literature approved by the Ethical Committee of Nippon Koukan Hospital. We obtained the patient's consent for publication of the present literature.

\section{Consent for publication}

Not applicable.

\section{Copyright}

(c) The Author(s) 2019.

\section{REFERENCES}

1. Aydin MV, Ozel S, Sen O, Erdogan B, Yildirim T. Intradural disc mimicking: a spinal tumor lesion. Spinal Cord 2004;42:52-4.

2. Epstein NE, Syrquin MS, Epstein JA, Decker RE. Intradural disc herniations in the cervical, thoracic, and lumbar spine: report of three cases and review of the literature. J Spinal Disord 1990;3:396-403.

3. Dandy WE. Recent advances in the diagnosis and treatment of ruptured intervertebral disks. Ann Surg 1942;115:514-20.

4. Choi JY, Lee WS, Sung KH. Intradural lumbar disc herniation--is it predictable preoperatively? A report of two cases. Spine J 2007;7:111-7.

5. D'Andrea G, Trillò G, Roperto R, Celli P, Orlando ER, et al. Intradural lumbar disc herniations: the role of MRI in preoperative diagnosis and review of the literature. Neurosurg Rev 2004;27:75-80.

6. Ruetten S, Komp M, Merk H, Godolias G. Full-endoscopic cervical posterior foraminotomy for the operation of lateral disc herniations using 5.9-mm endoscopes: a prospective, randomized, controlled study. Spine 2008;33:940-8.

7. Tamaki Y, Sakai T, Miyagi R, Nakagawa T, Shimakawa T, et al. Intradural lumbar disc herniation after percutaneous endoscopic lumbar discectomy: case report. J Neurosurg Spine 2015;23:336-9.

8. Matsumoto T, Toyoda H, Terai H, Dohzono S, Hori Y, et al. Utility of Discography as a Preoperative Diagnostic Tool for Intradural 
Lumbar Disc Herniation. Asian Spine J 2016;10:771-5.

9. Benyamin R, Vallejo R, Yousuf N, Tamrazi A, Kramer J. Incidental diagnosis of intradural lumbar disc herniation during discography: a case report. Pain Pract 2007;7:332-6.

10. Ducati LG, Silva MV, Brandão MM, Romero FR, Zanini MA. Intradural lumbar disc herniation: report of five cases with literature review. Eur Spine J 2013;22:S404-8. 